\title{
Three Concepts of Atlantic History
}

\section{Citation}

Armitage, David. 2002. "Three Concepts of Atlantic History”. In The British Atlantic World, 1500-1800, eds. D. Armitage and M.J. Braddick. Basingstoke and New York: Palgrave Macmillan.

\section{Permanent link}

http://nrs.harvard.edu/urn-3:HUL.InstRepos:29429085

\section{Terms of Use}

This article was downloaded from Harvard University's DASH repository, and is made available under the terms and conditions applicable to Other Posted Material, as set forth at http:// nrs.harvard.edu/urn-3:HUL.InstRepos:dash.current.terms-of-use\#LAA

\section{Share Your Story}

The Harvard community has made this article openly available.

Please share how this access benefits you. Submit a story.

Accessibility 
Armitage, David. "Three Concepts of Atlantic History". Armitage, D.; M J Braddick (Ed.).The British Atlantic world, 1500-1800.Houndmills, Basingstoke, Hampshire; New York: Palgrave Macmillan, 2002.

\section{Três Conceitos de História Atlântica}

Tradução: Juliana Jardim de O. e Oliveira

Revisão: Prof. Dr. Luiz Estevam Oliveira Fernandes.

Somos todos atlanticistas agora - ou assim parece ser diante da explosão do interesse pelo Atlântico e pelo mundo atlântico como objeto de estudos entre historiadores da América do sul e do norte, do Caribe, África e Europa ocidental. O Atlântico começa inclusive a moldar estudos de literatura, economia e sociologia sobre tópicos tão diversos quanto performance teatral, a história da primeira globalização e a sociologia de raça. Contudo, nenhum campo parece ter levado o Atlântico mais a sério e com mais entusiasmo do que a história. De fato, a história Atlântica foi considerada "um dos desenvolvimentos historiográficos mais importantes dos últimos anos”. A história Atlântica influencia o ensino de história em todos os níveis, especialmente nos Estados Unidos. Atualmente possui suas próprias conferências, seminários e programas de graduação; prêmios estão sendo distribuídos para os melhores livros escritos; e os primeiros livros didáticos começam a ser planejados. Este pode ser, portanto, um bom momento para se questionar justamente sobre o que é a história Atlântica e para onde ela caminha, antes que esta se torne entrincheirada e inflexível.

A atração pela História atlântica reside em parte, na natureza: afinal, não é um oceano um fato natural? O Atlântico parece ser uma das poucas categorias históricas que possui uma geografia interna, diferentemente das histórias produzidas sobre os Estados-nacionais, com suas fronteiras mutáveis e suas sobreposições imperfeitas entre lealdades políticas e fronteiras geográficas. A História atlântica também parece ter uma cronologia razoavelmente clara, que se inicia com a primeira travessia de Colombo em 1492 (ainda que, claro, ele tenha morrido sem conhecer as implicações de suas descobertas), e terminando, convencionalmente, com a era das revoluções no final do século dezoito e início do século dezenove. Existe, portanto, um pedigree 
diferenciado que identifica a História atlântica à 'primeira' ${ }^{1}$ modernidade, anterior ao início da industrialização, da democracia de massa, do Estado-nação, e de todas as clássicas definições de uma modernidade plena, uma condição cujas origens tanto Adam Smith quanto Karl Marx associaram às viagens de descobertas europeias e, especialmente, ao ano de 1492.

A geografia do atlântico deve ser considerada flexível, uma vez que 'oceanos' são tão míticos quanto os continentes. O Atlântico foi uma invenção europeia. Foi o produto de sucessivas ondas de navegação, exploração, colonização, administração e imaginação. O Atlântico não apareceu prontamente formado na consciência europeia mais do que a 'América' o foi. Apesar de certamente ser encontrado em mapas - e, portanto, na mentalidade - dois séculos antes da consciência da extensão total da América e o seu esboço. $\mathrm{O}$ atlântico foi uma invenção europeia não apenas porque os europeus foram seus habitantes, mas porque foram também os primeiros a conectar os seus quatro lados em uma única entidade, como um sistema e como uma representação de uma atributo natural discreto. Os limites precisos do oceano eram, claro, fluídos: o lugar exato onde ele terminava era menos claro do que aquilo que ele tocava e o que conectava, na medida em que 'o oceano' era pensado como um único corpo de água que circulava, e não como sete mares diferentes. A cronologia da História atlântica também deve ser considerada fluida. Uma metodologia atlântica já abriu estradas na história dos séculos dezenove e vinte adentro, ao menos desde que Daniel Walker Howe, em sua aula inaugural de 1993 em Oxford, clamou por uma agenda estendida no sentindo de colocar a história norte-americana em seu contexto atlântico; e, por exemplo, na história conectada de Daniel Rodger sobre política social na Europa e nos Estados Unidos no início do século XX, Atlantic Crossings: Social politics in a Progressive Age (1998); ou o estudo feito por Kevin O'Ruorke e Jeffrey Williamson sobre a globalização no mundo atlântico do século dezenove.

$\mathrm{O}$ fato de que essas questões fundamentais sobre a geografia e a cronologia da História atlântica possam sequer serem levantadas é sinal de que há atualmente, uma saudável auto-consciência do objeto de estudo. Até muito recentemente, contudo, a História atlântica era intermitente e sub-examinada como um objeto de estudo. Existiram historiadores do atlântico desde, pelo menos, o final do século dezenove. Aassim como, sabidamente, também já existiam histórias atlânticas. Mas foi apenas

\footnotetext{
${ }^{1}$ A expressão "primeira modernidade" aparece como a tradução para o período inicial da modernidade, séculos XV e XVI. Early modernity é a expressão utilizada no inglês.
} 
na última década, aproximadamente, que a História atlântica surgiu como um subcampo distinto, ou mesmo como uma sub-disciplina, dentro da profissão histórica. Apenas agora, um amplo grupo de historiadores e outros acadêmicos parecem ter feito do atlânticismo um fetiche.

E. P. Thompson certa vez afirmou que sempre que conhecia um novo deus ele sentia desejo de blasfemar. Muitos se sentiram da mesma maneira em relação à História atlântica e sua recente ascensão à proeminência. Seria a História atlântica capaz de revelar novos problemas ou ajudar historiadores a se perguntarem melhores questões do que as tradicionais áreas de questionamento, como as centradas em Estados-nacionais particulares, como o Reino Unido ou os Estados Unidos? Podem os historiadores terem esperanças de serem capazes de dizer qualquer coisa substancial sobre uma história que, em sua forma mais expansiva, conecta quatro continentes ao longo de cinco séculos? E, deste modo, não é a História atlântica um modo mais aceitável de estudar a história dos impérios marítimos Espanhol, Português, Britânicos e Holandês? Resumindo, o que torna a História atlântica um novo método para entender problemas genuínos, em detrimento de simplesmente uma licença para a superficialidade ou uma apologia ao imperialismo?

Se a blasfêmia é uma das resposta ao crescimento da História atlântica, é improvável que forneça boas respostas a essas importantes questões. Métodos mais proveitosos podem ser encontrados na genealogia - na história da História atlântica e na anatomia - nas formas que a História atlântica tem assumido e ainda pode assumir. No primeiro caso, Bernard Bailyn recentemente propôs uma genealogia da História atlântica que traça a sua origem nas correntes anti-isolacionistas da história norte-americana do século vinte. A linhagem particular de engajamento internacional que teria dado a luz à História Atlântica teve suas raízes na Primeira Guerra Mundial, e floresceu mais vigorosamente durante e após a Segunda Guerra Mundial. Jornalistas anti-isolacionistas como Walter Lippman e Forest Davis encontraram causas comuns aos historiadores, muitos deles católicos, primeiro na luta contra o Fascismo na Europa, e em seguida na luta inicial contra o comunismo na Guerra Fria. Para reunir seus aliados ideológicos, eles propuseram a ideia de que havia existido, pelo menos desde o Iluminismo, uma 'civilização' comum no mundo Atlântico Norte que ligava as sociedades norte-americanas (especialmente, claro, os Estados Unidos), à Europa por meio de um conjunto comum de valores pluralistas, democráticos e liberais. Este conjunto de valores teria sua própria genealogia, mais profunda, fundada em uma 
herança religiosa comum que passou a ser chamada, pela primeira vez e, nos mesmo círculos nos Estados Unidos dos anos 1940, de 'Judaico-cristã'. Assim, quando por exemplo, o historiador Carlton J. H. Hayes endereçou sua palestra como Presidente da American Historical Association, em 1945 no formato da questão: "The American Frontier - Frontier of What?", a resposta que ele deu foi bastante simples e muito ligada a seu próprio tempo: “da tradição Greco-romana e 'Judaico-cristã'. Dentro desse contexto, o Atlântico se tornou "o oceano interior da civilização ocidental", assim como o Mediterrâneo do império americano no pós-guerra. As histórias atlânticas produzidas no contexto imediato das consequências do pós-guerra - por exemplo, aquelas escritas por Jacques Godechot (Histoire de l'Atlantique [1947]), Michael Kraus (The Atlantic Civilization: Eighteenth-Century Origins [1949]), e R. R. Palmer (The Age of the Democratic Revolution [1959-63]) - subestimaram a centralidade do Atlântico para essa concepção de civilização. Esta ideia de Civilização Ocidental, portanto, devia mais à OTAN do que a Platão.

A história do comércio de escravos e da escravidão, e a história da África e dos africanos, e de forma mais geral, das raças, tiveram pouco ou nenhum papel nessa corrente da história Atlântica. Esta versão da 'civilização ocidental' era a história do Atlântico Norte, e não do Atlântico Sul, a história Anglo-americana mais do que Latino-americana, e das conexões entre a América e a Europa mais do que daquelas entre as Américas e a África. Tratava-se de uma história racialmente, se não necessariamente etnicamente, homogênea. A revolução em São Domingo - a maior e mais bem sucedida revolta de escravos no hemisfério ocidental, e evento culminante no ciclo de revoluções que havia sacudido o mundo Atlântico desde 1776 - não foi um evento interno a essa versão da história Atlântica e, portanto, não apareceu na obra de Palmer, Age of the Democratic Revolution. Nem foram os praticantes da história do Atlântico negro reconhecidos como participantes de um empreendimento historiográfico comum. W.E.B. Du Bois, C. L. R. James, e Eric Williams, para tomar os três exemplos mais proeminentes, perseguiram objetos que eram, obvia e conscientemente Atlânticos dentro do seu escopo - as dinâmicas do tráfico de escravos e a abolição, a relação entre escravismo e industrialismo, a revolução Haitiana em si - mais de 60 anos antes dos sucessos da História Atlântica serem ligadas ao surgimento da OTAN. A contribuição de décadas destes autores ao campo, fornece uma genealogia mais longa, mais multi-étnica e mais genuinamente internacional do que a esposada pela maioria dos proponentes do Atlântico branco 
que, como muitos outros genealogistas, ignoraram esses ancestrais inconvenientes ou incompatíveis.

Recentemente a História Atlântica tem se tornado mais multicolorida. O próprio Atlântico branco se tornou um campo de estudo autoconsciente mais do que um modelo definidor para todas as outras histórias atlânticas. $\mathrm{O}$ atlântico negro da diáspora africana se juntou ao atlântico verde da dispersão política e demográfica irlandesa. Hoje existe até mesmo um atlântico vermelho, escrito a partir do marxismo, que descreve a formação de uma classe trabalhadora multinacional, multiétnica e multicultural no mundo atlântico inglês, formando uma 'hidra de muitas cabeças' aos olhos de seus mestres. Isto pouco tem em comum com as tradicionais histórias políticas do atlântico branco e muito com os estudos culturais do atlântico negro, especialmente o trabalho de Paul Giroy em o The Black Atlantic (1993), que considera o atlântico como o cadinho de uma modernidade definida pela agitação e dispersão, mobilidade de massa e hibridismo cultural. A história atlântica não está mais disponível em nenhuma cor, por todo o tempo que foi branca.

O método genealógico para a História Atlântica expõe um atlântico branco com raízes na Guerra Fria, um atlântico negro com origens no pós-Guerra Civil americana nos Estados Unidos, e um atlântico vermelho que remonta ao cosmopolitismo de Marx. Seus ancestrais radicalmente diferentes podem, eles mesmos, ter impedido qualquer reconciliação entre essas diferentes linhagens de História Atlântica até o advento de uma era supostamente pós-ideológica - isto é, tanto pós-Guerra Fria quanto pós-imperial. A emergências de histórias atlânticas multicoloridas, e de histórias do mundo atlântico que englobem mais do que o Atlântico norte anglófono, testemunham o sucesso de uma fertilização-cruzada.

Baseando-me neste sucesso, eu gostaria agora de me dirigir à anatomia da história Atlântica para propor uma tipologia tripla de História Atlântica. Como toda boa tricotomia, esta deve ser exaustiva, mas não exclusiva: deve cobrir todas as formas concebíveis de História Atlântica, mas não prelude a sua combinação. Então, tendo isto em mente, deixe-me oferecer esses três conceitos de História Atlântica:

1 - História circum-Atlântica - a história transnacional do mundo Atlântico.

2 - História trans-Atlântica - a história internacional do mundo Atlântico.

3 - História cis-Atlântica - a história nacional ou regional dentro de um contexto Atlântico. 
Meu objetivo no que segue é descrever cada método, considerando sua utilidade e sugerir sua relação com as outras duas formas. Darei atenção particular ao terceiro conceito, História cis-Atlântica - tanto porque ele demanda maior atenção, quanto porque pode se provar o mais útil como um meio de integrar histórias nacionais, regionais ou locais em perspectivas mais amplas sustentadas pela História Atlântica. Também questionarei a titulo de conclusão, quais são as limitações da História Atlântica, como exemplo de história oceânica e também como um modo de questionamento histórico em voga no mundo de língua inglesa.

\section{História circum-Atlântica}

A História circum-Atlântica é a história Atlântica como uma zona particular de trocas e inter-trocas, circulação e transmissão. É, portanto, a história de um oceano como uma arena distinta de qualquer uma das zonas oceânicas particulares e mais estreitas que a compõem. Esta área certamente abrange as costas do atlântico, mas apenas na medida que estas margens formam parte de uma história oceânica maior do que um conjunto de histórias nacionais e regionais especificas que desembocam no Atlântico. É a história das pessoas que cruzaram o atlântico, que viveram em seu litoral e que participaram das comunidades que foram ali possíveis, de seu comercio, e de suas ideias, assim como das doenças que carregavam, a flora que transplantaram e a fauna que transportaram.

A história circum-Atlântica talvez seja a forma mais auto-evidente de se trabalhar a história Atlântica. Contudo, dos três conceitos possíveis de história atlântica, é o que foi menos investigado. Foi apenas na última década que este conceito de história Atlântica obteve renome em um brilhante trabalho sobre estudos em performance teatral, feito pelo historiador de teatro Joseph Roach, intitulado Cities of the dead: Circum-Atlantic Performance (1996). 'O mundo circum-atlântico como emergiu das economias revolucionárias do final do século dezessete', escreve Roach, ‘... se assemelhava a um vortex no qual commodities e práticas culturais mudavam de mãos muitas vezes'. Desta maneira, 'o conceito de um mundo circum-Atlântico (em oposição a um mundo transatlântico), insiste na centralidade das histórias diaspóricas e genocidas da África e das Américas, Norte e Sul, na criação da cultura da modernidade. 
Esta é a história circum-Atlântica em dois sentidos: ela incorpora tudo $a o$ redor da bacia atlântica, e é móvel e conectiva, traçando circulações pelo mundo atlântico. Havia, claro, muitas zonas menores de trocas ao redor das franjas da bacia atlântica, seja na África ocidental, na Europa ocidental ou ao redor do Caribe, que tinha características semelhantes. Tais sistemas menores existiram dentro de culturas marítimas mais limitadas que haviam desenvolvido suas próprias identidades e interdependência milhares de anos antes da viagens de Colombo. A grande realização europeia foi ligar essas sub-zonas a um único sistema atlântico. Dentro desse sistema havia uma contínua interação entre as sociedades que os migrantes haviam deixado e aquelas que eles criaram em conjunto do outro lado do atlântico: é justamente essa realização que nos permite afirmar que o Atlântico foi uma invenção europeia, ao mesmo tempo que reconhecemos a contribuição de povos não-europeus a esse desenvolvimento. Em contraste, as sub-zonas do Oceano Índico tinham sido integradas muito antes da chegada dos portugueses ou de outros europeus. Alguns comentadores têm observado a história do mundo atlântico na primeira modernidade como 'uma espécie de precursor da globalização na virada do século vinte e um'. No entanto, essa visão negligencia a integração precoce do oceano índico, sem mencionar a integração do mediterrâneo.

A maioria das histórias circum-atlânticas têm seguido o modelo do "Atlântico branco" e enfatizaram a integração em detrimento da circulação. Histórias circumatlânticas alternativas que foram inspiradas pela história do atlântico negro têm destacado a mobilidade em detrimento da estabilidade e, como resultado, tem se mostrado menos whiggish ${ }^{2}$. Nas palavras de Paul Gilroy, o Atlântico foi um caldeirão de 'criolização, miscigenação, mestiçagem e hibridismo'; desse caldeirão de identidades teria emergido o que Roach chamou de uma 'intercultura... ao longo da costa atlântica'. Este interesse na cultura e na identidade em detrimento do comércio ou da política tem direcionado a atenção à fluidez do processo de troca ao invés de uma rigidez nos resultados desse processo. Assim, estamos cada vez menos impelidos a escrever a História atlântica dentro de narrativas lineares, seja da modernização ou da globalização.

\footnotetext{
2 "Whiggish" é uma adjetivação referente ao termo "Whig", palavra utilizada para denominar os partidos e os políticos conservadores, tanto no âmbito da política inglesa quanto da norteamericana.
} 
A história circum-atlântica é a história transnacional. Sua cronologia convencional começa justamente no período associado ao surgimento do Estado, ou seja, no final do século quinze e inicio do século dezesseis, e termina pouco antes da época dos Estados nacionais, em meados do século dezenove. Impérios e monarquias compostas, e não Estados, foram as unidades políticas características dessa era. A história do mundo Atlântico tem sido contada muitas vezes como a somatória das histórias desses impérios, mas tal história teria necessariamente que englobar apenas uma perspectiva europeia sobre o sistema atlântico. Uma verdadeira história circumatlântica elude, a história dos Estados nacionais cronologicamente e ultrapassa as fronteiras dos impérios geograficamente, como a barra de prata que foi levada do império espanhol americano para dentro da China, criando uma ligação entre o mundo atlântico e o comercio asiático que foi identificado como o ponto inicial para uma economia verdadeiramente global no século XVI.

Como a história de uma região, seus produtos, e seus habitantes, a história circum-atlântica é, portanto, um exemplo clássico de uma história oceânica transnacional: clássico, mas não definidor, porque, diferentemente do mediterrâneo de Braudel, ela não conforma uma unidade única que seja identificável climática e geograficamente. Como Braudel mesmo notou, 'o atlântico, que se estende de polo a polo, reflete as cores de todos os climas da terra'. Ele é, portanto, por demais diverso na variedade de zonas climáticas que abrange - do Ártico aos cabos, e das regiões costeiras da Europa ocidental ao arquipélago caribenho - para que o determinismo geográfico tenha qualquer poder explicativo. $\mathrm{O}$ atlântico se assemelha ao oceano índico nessa variedade, bem como pelas ligações culturais e econômicas forjadas em seu interior, mas não na medida em que essas ligações precederam de longa data a intervenção europeia. E, se o oceano índico foi precoce nesse sentido, o pacifico estava atrasado, quando comparado aos parâmetros atlânticos. O pacífico também teve expansivas subzonas que haviam sido criadas pelas culturas marítimas polinésias milhares de anos antes da entrada dos europeus, mas ele também foi, em última análise, uma criação europeia, no sentido de que foram os europeus que o conceberam como um todo; também foram os europeus que primeiramente o distinguiram de seu vizinho e tributário, o atlântico. Ainda assim, para todas essas diferenças significativas, as histórias oceânicas do mediterrâneo, do oceano índico, do atlântico e do pacífico, compartilham uma característica definidora importante: como histórias especificamente oceânicas (para além de histórias marítimas ou imperiais, por 
exemplo) elas agregam a terra e o mar em uma relação 'simbiótica, mas assimétrica': ou seja, em que os dois são interdependentes, mas a história do oceano predomina ao mesmo tempo em que não é o único objeto de estudo, como seria numa história estritamente marítima. As histórias nacionais de estados territoriais ou impérios são apenas parte dessa história, na medida em que o oceano cria conexões de longadistância entre eles. Destarte, como todas as histórias oceânicas, a história circumatlântica é transnacional, mas não internacional. Ao invés, esta é a província do que pode ser chamado de história 'trans-Atlântica'.

\section{História trans-Atlântica}

A história trans-Atlântica é a história do mundo atlântico contada através de comparações. A história circum-atlântica torna a história trans-Atlântica possível. O sistema de circulação do atlântico criou ligações entre regiões e pessoas antes separadas. Isto permitiu aos historiadores trans-atlânticos delinearem comparações significativas - e não meramente arbitrárias - entre histórias que seriam, de outro modo, distintas. Diferentemente das relações 'simbióticas, mas assimétricas' entre terra e mar traçadas pela história atlântica como uma história oceânica, a história trans-atlântica se concentra na região costeira do oceano e admite a existência de nações e Estados, bem como de sociedades e formações econômicas (como plantações e cidades) ao redor do litoral atlântico. A história trans-atlântica pode trazer comparações significativas entre essas diferentes unidades porque estas já compartilham características comuns, uma vez que estão entrelaçadas em relações circum-atlânticas. A história atlântica comum dessas unidades define, mas não determina, a natureza das conexões entre entidades diversas; esta pode ser excluída da comparação como uma variável comum, mas pode tornar-se ela mesma objeto de estudo dentro de uma história especificamente circum-atlântica.

A história trans-atlântica pode ser chamada de história internacional por duas razões. A primeira razão é etimológica e contextual; a segunda, comparativa e conceitual. Ambos os termos - 'trans-atlântico' e 'internacional' - foram inseridos na língua inglesa durante a guerra de independência norte-americana. Os primeiros usos do termo 'trans-atlântico' podem ser encontrados na Inglaterra entre 1779-81. Os primeiros ingleses a usarem o termo, como Richard Watson (Bispo de Llandaff) e o historiador Charles Henry Arnold, de modo geral utilizaram-no em um sentido mais preciso do que o empregado aqui, ou, de fato, mais preciso do que seu sentido 
convencionalmente utilizado nos dias de hoje, ou seja: 'através e do outro lado do Atlântico', como Bretões da 'irmandade bretã' na América do Norte; ou na 'presente guerra trans-atlântica' sendo lutada na e pela América britânica. Apenas John Wilkes utilizou o termo em seu sentido moderno, quando se referia a uma 'viagem transatlântica'.

O termo 'internacional' emergiu exatamente no mesmo momento, mas em um contexto ligeiramente diferente, nos escritos legais de Jeremy Bentham. Em seu Introduction to the Principles of Morals and Legislation (1780/89), Bentham buscou definir um segmento particular da lei que, como hoje, ainda não possui clara definição em inglês. Tratava-se das leis entre Estados como agentes soberanos, distinto do que havia sido tradicionalmente chamado de 'lei das nações' ou uma lei que se aplicava a todas as pessoas como membros de grandes sociedades políticas ou étnicas. 'A palavra 'internacional' ... é nova', escreveu Bentham. 'Ela é calculada para expressar, em mais de uma maneira significativa, o braço da lei que está comumente denominado como lei das nações'. O contexto era diferente apenas no sentido de que Bentham endereçou o seu neologismo a colegas advogados, em um trabalho escrito em 1780, publicado somente em 1789. Entretanto, era parecido no sentido de que Bentham havia se tornado um observador interessado e, de fato, profundamente engajado na guerra americana, sendo também co-autor da única resposta formal à Declaração de Independência feita pelo governo britânico em 1776.

No entanto, há mais elementos do que essa origem comum no contexto na guerra Americana que identificam a história trans-atlântica com a história internacional. Assim como a história internacional pode ser considerada como a história das relações entre nações (ou, na realidade, Estados) dentro de um sistema político e econômico maior, também a história trans-atlântica une Estados, nações e regiões dentro de um sistema oceânico. A história trans-atlântica é especialmente adequada às histórias do mundo atlântico dos séculos dezessete e dezoito, quando a formação dos Estados nacionais andava de mãos dadas com a formação dos impérios, criando um processo convergente que podemos chamar de 'construção do Estado imperial'. E é particularmente útil como um método para as histórias daqueles Estados atlânticos que tendem mais ao excepcionalismo em sua história, como, por exemplo, o Reino Unido e os Estados Unidos - mas cujos traços comuns podem ser escavados e demonstrados mais claramente dentro de um quadro transatlântico de comparação. 
A história trans-atlântica como uma história comparada tem sido mais frequentemente conduzida a partir de um eixo norte-sul do mundo atlântico. Portanto, têm sido realizada mais comumente como um exercício em história inter-imperial do que em história internacional. Os primeiros estudos nessa linha, notadamente o ensaio de Tannenbaum de 1946 sobre a escravidão na América espanhola e britânica, e a posterior comparação de Herbert Klein da escravidão ibérica e britânica, bem como o trabalho de J. H. Elliot, ainda em curso e muito mais abrangente, sobre os impérios espanhol e britânico nas Américas, em que compara os impérios ibéricos e britânicos de acordo com os seus diferentes sistemas de lei, regulação econômica, crenças religiosas, ou estrutura institucional. Contudo, o potencial comparativo entre histórias trans-atlânticas ao longo do eixo Leste-Oeste permanece ainda largamente inexplorado. Nos exemplos em que a empreitada foi levada a cabo, como nos trabalhos de Bernard Bailyn e John Clive, examinando a Escócia e os Estados Unidos $^{3}$ como 'províncias culturais' da metrópole inglesa, ela tem sido geralmente realizada dentro dos quadros imperiais, muitas vezes explicitamente divida entre centro e periferia.

Ainda assim, as unidades de análise poderiam ser maiores e o quadro mais generoso. Tomando o exemplo do atlântico anglófilo: ainda não há nenhuma comparação sistemática entre o Reino Unido e os Estados Unidos como uniões políticas duradouras do século dezoito. O Reino Unido foi criado pelo Tratado de União de 1707; os Estados Unidos inicialmente anunciados na Declaração de Independência, estavam unidos pelos Artigos da Confederação e apenas na Constituição de 1788 produziram uma união mais duradoura. Ambos podem ser vistos em retrospecto por terem conjugado a formação do Estado com um nacionalismo fictício: os britânicos o forjaram através de um antagonismo com a França católica (ao longo do século dezoito e adentrando o século dezenove), os norte-americanos como o resultado, mais do que condição para a independência e a vitória na guerra. Ambos definiram a cidadania politicamente mais do que etnicamente, de modo que nenhum dos dois conformaram a visão primordialista clássica de formação do Estado-nação como a realização política de uma identidade imemorial. Cada um permanece definido pelas suas origens no século dezoito, e essas definições podem ser traçadas em suas relações trans-atlânticas: a norte-americana,

\footnotetext{
3 Em muitos momentos no texto é preciso distinguir o uso da palavra "América”. Neste caso, refere-se aos Estados Unidos da América.
} 
em parte devido às ligações duradouras com o Reino Unido e o seu esforço para assegurar a independência; a britânica, em parte devido ao impacto da derrota na guerra Americana ${ }^{4}$, tendo como consequência, a recriação da nação. A esses dois produtos políticos da guerra, podemos somar também a América do Norte britânica, posteriormente Canadá, compondo os três Estados forjados no ultimo quarto do século dezenove, unidos em uma história atlântica comum. Elas podem ser utilmente comparadas em relação às suas origens, seus caminhos divergentes desde o final do século dezessete, e sua história comum dentro do mundo atlântico anglófilo.

A comparação como uma ferramenta histórica pode utilmente revelar diferenças, mas a sua viabilidade depende de alguma similaridade inicial. Uma história dentro do contexto imperial, e uma história de resistência a um império fornecem nítido ponto de comparação entre as repúblicas dos Estados Unidos e da América Latina, apesar de suas divergentes origens institucionais e distintas tradições de religião, governança e relações inter-étnicas também revelarem diferenças intratáveis. Tais comparações podem ajudar a definir mais precisamente as características históricas de segmentos do mundo atlântico, mas apenas dentro do contexto daquela perspectiva trans-atlântica maior. Tal definição mais precisa, levada uma etapa adiante, e fora do contexto comparativo, é o objetivo do terceiro e último conceito de história atlântica, a história cis-Atlântica.

\section{História cis-Atlântica}

A História 'cis-atlântica' estuda lugares particulares como localidades singulares dentro de um mundo atlântico e busca definir essa singularidade como o resultado da interação entre particularidades locais e uma rede mais ampla de conexões (e comparações). O termo 'cis-Atlântico' pode parecer um neologismo bárbaro, mas como os termos 'trans-atlantico', e 'internacional', ele também foi gestado no final do final do século XVIII. Seu progenitor foi Thomas Jefferson, e o barbarismo, se deve não à cunhagem mesma do termo, mas à condição contra a qual Jefferson o fez. Este barbarismo - assim como a debilidade e encolhimento - haviam sido imputados à fauna do Novo Mundo por naturalistas europeus, como o Conde de

\footnotetext{
${ }^{4}$ Novamente, a "guerra Americana" refere-se à guerra no processo de independência das treze colônias, posteriormente Estados Unidos da América.
} 
Buffon. Jefferson, em seu Notes on the State of Virginia (1795) ${ }^{5}$, o respondeu aduzindo uma riqueza de informações para rebater as acusações baseadas (de acordo com ele), em mera ignorância e preconceito.

Eu não pretendo negar que existem variações na raça humana, distintas pelos seus poderes de corpo e de mente. Acredito que essas variações existem, como acredito ser o caso nas raças de outros animais. Eu apenas pretendo sugerir uma duvida, se as capacidades e faculdades dos animais dependem do lado do Atlântico em que cresce seu alimento, ou que fornece os elementos dos quais eles são constituídos? Se a natureza se alistou como um partidário cis ou trans atlântico. ${ }^{6}$

Jefferson, portanto, utilizou o termo para significar 'deste lado do atlântico', para distingui-lo do mundo trans-atlântico europeu, um significado que ele ampliou politicamente quando disse a James Monroe em 1823 que era interesse dos Estados Unidos jamais sofrer a interferência da Europa em assuntos cis-atlânticos. Deste modo, o termo foi tanto uma bandeira da diferença quanto uma marca de uma nova perspectiva americana na medida em que foi definido em relação ao oceano Atlântico.

A história cis-Atlântica, no sentido mais amplo aqui proposto, é a história de qualquer lugar particular - uma nação, um Estado, uma região e mesmo uma instituição especifica - em relação ao mundo atlântico mais vasto. O maior monumento de história cis-atlântica provavelmente ainda é o trabalho de oito volumes de Huggette e Pierre Chaunu Seville et l'Atlantique (1955-9), que se expandiu a partir de uma única cidade e abarcou o mundo atlântico inteiro. Trabalhando quase que de modo reverso, uma história cis-atlântica foi levada a cabo, mesmo que não sob essa denominação precisa, por geógrafos historiadores como D. W. Meining e E. Estyn Evans, ou, mais recentemente, pelo arqueólogo Barry Cunliffe, em seus estudos sobre a 'América Atlântica' (Meinig), 'Europa Atlântica' (Evans), ou a ampla zona cultural

\footnotetext{
${ }^{5}$ Notas Sobre o Estado da Virgínia, de 1785, é um dos mais clássicos textos de Thomas Jefferson, no qual ele compila importantes achados e informações sobre os recursos naturais e a economia do estado da Virgínia, bem como tece considerações sobre suas ideias e crenças políticas. Ali, Jefferson escreveu também sobre a natureza da boa sociedade, sobre a escravidão e os problemas relativos à miscigenação. É considerado um importante texto também dentro do que se convencionou chamar de "debate sobre o novo mundo", protagonizado por De Paw e Buffon, e teve também importante participação do Abade Raynal, no qual a grandiosidade ou a degeneração da natureza americana foi colocada em pauta. 0 texto está disponível na íntegra em: http://books.google.com.br/books?id=UO0OAAAAQAAJ\&printsec=frontcover\&dq=\%22Notes $+o$ $\mathrm{n}+$ the + State + of + Virginia $\% 22 \& \mathrm{hl}=\mathrm{pt}-$

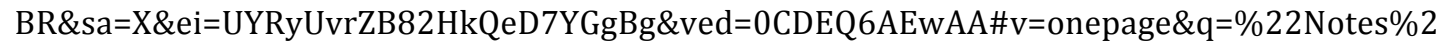
0on $\% 20$ the $\% 20$ State $\% 20$ of $\% 20$ Virginia $\% 22 \& f=$ false

${ }^{6}$ Tradução livre.
} 
'voltada para o oceano' da Groenlândia às ilhas Canárias (Cunliffe). Os trabalhos desses autores integram regiões aparentemente díspares dentro de um contexto atlântico comum geograficamente, culturalmente e politicamente. O oceano atlântico e a relação comum entre este e as suas regiões, fornece o elo, mas não é, por si só o objeto de estudo. Este método se aproxima da história circum-atlântica, mas se concentra não apenas no oceano em si, e mais na maneira como regiões especificas foram definidas por suas relações com este oceano. Estas relações ao longo do tempo permitem que acadêmicos como Meinig, Evans e Cunliffe descrevam padrões mais amplos e descendam dessas amplas ligações para o impacto particular das relações atlânticas sobre regiões especificas. Cunliffe, por exemplo, inicia seu trabalho na préhistória e termina pouco antes do inicio da primeira modernidade; de maneira similar, Meinig abraçou a história de um continente inteiro até o século vinte. A metodologia utilizada por eles sugerem o que pode ser alcançado pelas histórias cis-atlânticas no inicio do período moderno (e para além) se eles se concentram em unidades de análise menores e recortes temporais menos extensos.

A história cis-atlântica pode superar divisões artificiais, mas duradouras entre histórias normalmente distintas umas das outras, interna e externa, doméstica e estrangeira, nacional e imperial. O surgimento da história nacionalista no século dezenove coincidiu com a invenção de histórias extra-nacionais, seja uma história diplomática ou da expansão imperial. As fronteiras entre tais histórias permaneceram, em sua maioria, impermeáveis até recentemente, ou até o surgimento do multilateralismo pós-guerra, da descolonização, e da criação de federações transnacionais, ao lado do sentimento separatista em um nível sub-nacional que, juntos, ajudaram a dissolver algumas dessas fronteiras. Narrativas maiores de desenvolvimento histórico podem ser mais difíceis de serem desalojadas. Por exemplo, os processos implicados no uso dos rótulos 'primeira modernidade' na história europeia, e "colonial" nas histórias da América britânica ou espanhola são distintos: 'primeira modernidade' implicava em um movimento em direção a modernidade, enquanto 'colonial' denotava subordinação dentro de um império que precederia a independência e a aquisição dos status de nação e Estado. O rótulo de “primeira modernidade", raramente, se é que alguma vez, foi aplicado à história da América Latina, e as tentativas de encorajar a substituição de 'colonial' por 'primeira modernidade' na história norte-americana não foram inteiramente bem-sucedidas. A incompatibilidade de tais master-narrativas tem sido especialmente debilitadoras em 
estudos do período chamado, variavelmente, de 'primeira modernidade' e 'colonial'; não menos porque tem obscurecido continuidades entre processos normalmente colocados de maneira separada, como o processo de formação do Estado nacional dentro da Europa e a formação dos impérios para além dela. Assim como as comparações possíveis através da história trans-atlântica, também a história cisatlântica confronta tais separações ao insistir nos aspectos comuns e ao estudar os efeitos locais dos movimentos oceânicos.

A história cis-atlântica, nesse nível local, pode ser mais frutífera quando aplicada a lugares mais claramente transformados por suas ligações atlânticas: cidades e vilas portuárias. Por exemplo, a economia da cidade de Bristol passou de uma dependência do comercio de vinho no século quinze, se concentrando em produtos básicos no atlântico no século dezessete. Isto envolveu não apenas uma reorientação radical de leste para oeste, e da Europa para as Américas, mas também levantes na ordem social, na disposição do espaço cultural e na distribuição de poder. Transformações similares podem ser traçadas em outros assentamentos ao redor da bacia atlântica, seja nas costas europeias ou africanas, nas cidades caribenhas ou ao longo da costa ocidental da América do Norte. Pontos entrecruzados dentro do mundo atlântico, por exemplo, ganharam novo significado quando as rivalidades entre impérios aumentaram e políticos locais tiraram vantagem dessa competição para suas alianças, como entre os índios Kuna do istmo de Dárien. Em qualquer lugar onde as populações locais se encontravam ou se chocavam com estrangeiros (nem sempre europeus), 'meio-termos' de negociação e contestação como este surgiram, e que não teriam existido se não fosse pela circulação e competição criados pelo alargamento das conexões dentro do sistema atlântico. Da mesma maneira, novas economias surgiram para suprir novas demandas, seja pelo grosso da exportação do sistema de plantation do mediterrâneo para as Américas nos séculos XVI e XVII, ou um surgimento mais orgânico por uma gradual especialização, como a dos produtores de vinho de Madeira no século XVIII, que criaram seus lendários vinhos em resposta direta ao gosto dos consumidores. $\mathrm{O}$ maior potencial para a história cis-atlântica pode estar na história de lugares ainda maiores que cidades, istmos, ou ilhas, ou seja, nas histórias das nações e estados voltados para o oceano atlântico. As histórias dos três reinos da Grã-Bretanha e da Irlanda, no início do período moderno nos fornecem um importante conjunto de comparações interligadas. Tal método cis-atlântico (ainda que não sob esta denominação), caracterizou a escrita da História da Irlanda desde a 
década de 1930, quando historiadores como G. A. Hayes McCoy e David Beers Quinn começaram a colocar a história irlandesa dentro do contexto de expansão para o oeste. Uma linha mais recente na historiografia irlandesa tem, inversamente, ressaltado as similaridades entre o lugar da Irlanda dentro de um monarquia britânica composta e a situação de outras províncias, como a Boêmia, dentro dos impérios europeus e monarquias compostas contemporâneas. Certamente, a Irlanda era parte dos padrões pan-Europeus de confessionalismo, militarização e formação do Estadonacional, mas ela dividiu experiências igualmente com outras colônias atlânticas britânicas que, somadas, a definiram como uma 'unidade política semi-atlântica, com algumas características tanto do Novo Mundo quando do Velho'. De modo similar, também a Escócia aparece agora menos como uma 'província cultural' da Inglaterra do que como uma nação atlântica, ainda que uma nação que pesasse as alternativas de migração e comercio com a Europa do norte em relação às novas oportunidades oferecidas pelos empreendimentos a oeste. Desde o inicio do século XVII seus habitantes buscaram, de modo intermitente, "novas" Escócias nas Américas, mesmo que se tenha afirmado que alguns presbiterianos ingleses em 1638 tivessem buscado uma 'América na Escócia' mais religiosamente tolerante, durante a Guerra dos Bispos. Ao final do século XVIII, mesmo as terras altas escocesas estavam profundamente entrelaçadas dentro da política econômica do Mundo Atlântico, na medida em que a exportação de soldados para os exércitos imperiais britânicos se tornou 'simplesmente uma das economias especializadas que emergiu da inclusão da região dentro do império - equivalente ao comercio de Tabaco de Gaeldom.

Os ingleses foram atlanticistas precoces e entusiásticos em comparação com os irlandeses e escoceses, mas uma história cis-atlântica da Inglaterra na primeira modernidade ainda permanece como a menos desenvolvida de todas aquelas que podem ser aplicadas aos três reinos. Isso se torna ainda mais curioso uma vez que muitas das características definidoras da primeira modernidade na Inglaterra unia processos dentro da própria Inglaterra àqueles do mundo atlântico.

Temos hoje, por exemplo, uma imagem muito mais clara do que antes das continuidades entre migrações internas e externas, de modo que podemos ver a migração para o mundo atlântico (e muitas vezes dentro dele) como a extensão da mobilidade interna à Inglaterra, especialmente na medida em que esta era canalizada através de portos-chave, como Londres e Bristol, no século dezessete. A política é suscetível à mesma análise. Como argumentou recentemente o autor Michael 
Braddick, o Estado inglês nesse período colonizou dois tipos de espaços simultaneamente, pela intensificação de sua autoridade sobre a própria Inglaterra e pela extensão dessa autoridade sobre territórios muito além da Inglaterra. A necessidade de cooptar as elites locais para garantir simbolicamente a autoridade provou ser um problema comum em ambas as arenas. De modo similar, a criação de uma economia atlântica não foi simplesmente uma questão de encontrar novos mercados no exterior, mas também envolveu a crescente implicação da economia doméstica nas trocas atlânticas, mesmo antes da revolução comercial do século dezoito. As dimensões deste envolvimento no comércio atlântico ainda precisam ser investigadas nos níveis mais íntimos de cidades, vilas e até mesmo domicílios. A história cis-atlântica terá, portanto, que abarcar tanto a mais ampla extensão do Estado inglês quando o mais intimo foco da esfera doméstica. Ao tratar cada problema como parte de uma mesma experiência atlântica em desenvolvimento, poderá ser possível fornecer relatos das relações entre o Estado, o mercado e a família, mais complexos e persuasivos do que o que se fez até então.

Braudel nos advertiu que 'o Mediterrâneo histórico parece ser um conceito de infinita expansão', e se questionou em voz alta: 'Mas, quão longe no espaço se justifica a sua extensão?'. Pode-se fazer o mesmo questionamento sobre o Atlântico e sobre a história atlântica. A história circum-atlântica parece não se estender para além das costas do oceano; e, portanto, assim que saímos do sistema de circulação do atlântico em si, entramos em uma serie de histórias cis-atlânticas. A história transatlântica combina tais histórias cis-atlânticas em unidades comparativas; as possibilidades de combinação são inúmeras, mas não infinitas, porque as adjacências ao Atlântico determinam as possibilidades de comparação. As histórias cis-atlânticas, ainda que superficialmente as mais precisamente unidas, podem, de fato, ser as de maior extensão: tais histórias se lançam profundamente nos continentes da costa cisatlântica, na mesma profundidade que bens, ideias, e pessoas circulavam dentro do sistema atlântico. Histórias cis-atlânticas de regiões completamente interioranas seriam então possíveis.

Os três conceitos de história atlântica aqui delineados não são excludentes, mas se reforçam. Em conjunto, eles oferecem a possibilidade de uma história tridimensional do mundo atlântico. Uma história circum-atlântica se repousaria sobre os frutos de várias histórias cis-atlânticas gerando comparações entre elas. A história trans-atlântica pode ligar essas histórias cis-atlânticas devido à existência de um 
sistema circum-atlântico. A história cis-atlântica, por sua vez, alimenta as comparações trans-atlânticas. Este conjunto de histórias em "fertilização cruzada" pode mostrar que a história Atlântica é a única história oceânica que possui estas três dimensões conceituais, porque talvez seja a única que pode ser construída ao mesmo tempo a partir de um recorte transnacional, internacional e nacional. Comparações globais entre diferentes histórias oceânicas ainda não foram sequer imaginadas, mas devem ser centrais para qualquer história oceânica futura.

A História Atlântica ainda não foi morta por milhares de livros-textos como aconteceu com outros campos de estudo. Ela ainda não possui um consenso canônico de problemas, eventos ou processos. Ela não segue um método ou prática comuns. A História Atlântica começou, inclusive, a escapar produtivamente das fronteiras da primeira modernidade (entre 1492-1815), dentro da qual ela tem sido mais usualmente confinada. Como o próprio atlântico, o campo é fluido, em movimento e potencialmente sem fronteiras, dependendo do modo como é definido. Isto faz parte de seu atrativo, mas é também uma de suas desvantagens. É improvável que ela substitua as tradicionais histórias nacionais e irá competir com outras formas de histórias transnacionais e internacionais. Contudo, como um campo que liga histórias nacionais, facilita a comparação entre elas e que abre novos campos de estudo ou amplia o foco de questionamentos já consolidados, certamente este tipo de história apresenta mais oportunidades do que desvantagens. A história Atlântica - seja circum-atlântica, trans-atlântica ou cis-atlântica - impulsiona os historiadores em direção a um pluralismo metodológico e horizontes mais amplos. Isto é certamente grande parte do que se pode esperar de qualquer campo emergente. 